\title{
ALÉM DA LAMA E DO LIXO: MOVIMENTOS DE ESCOLARIZAÇÃO EM SÃO PEDRO, VITÓRIA/ES (1977-2007)
}

RESUMO: Discute o processo histórico de escolarização da infância no bairro São Pedro I, em Vitória/ES. Relaciona-o com o movimento de constituição da região na década de 1970. Toma como lócus o CMEI da Amizade, instituição que acompanha a primeira referência de espaço educativo. Privilegia como fonte o relato dos sujeitos residentes no bairro, expressos em dois livros sobre o movimento de constituição da região, escritos por uma moradora, e uma obra produzida por pesquisadores, moradores e a Prefeitura de Vitória. Também destaca as narrativas de uma cozinheira e de uma auxiliar de serviços gerais, profissionais da instituição pesquisada. As fontes são analisadas como "testemunhos", como conhecimento através de "vestígios". Procura compreender os "usos táticos" e "estratégicos" praticados pelos sujeitos na mobilização popular, na organização das moradias e instituições educativas, bem como os reflexos dessa experiência para os que permanecem no CMEI educando crianças, atualmente.

Palavras-chave: Movimentos Sociais; Escolarização; Narrativas.

* Doutoranda em Educação pela Universidade Federal do Espírito Santo (UFES); Professora do Centro de Educação da Universidade Federal do Espírito Santo (UFES); Pesquisadora do Grupo PROTEORIA e do Grupo NUPEC3. Email: keziaxe@gmail.com

* * Doutor em Educação pela Universidade Metodista de Piracicaba (UNIMEP); Professor do Programa de Pós-Graduação em Educação Física da Universidade Federal do Espítico Santo (UFES) e Pesquisador do Grupo PROTEORIA. E-mail: amarilioviz@gmail.com 


\section{BEYOND THE MUD AND THE WASTE: \\ SCHOOLING MOVEMENTS IN SAN PEDRO, VICTORIA/ES (1977-2007)}

ABSTRACT: This paper discusses the historical process of schooling in childhood in the neighborhood of San Pedro I, in Victoria, E.S. It looks at the constitutional movement of the 1970s in the (E.S.) region. As its focal point, it takes "CMEI da Amizade", an institution that follows the first reference to educational space. It has as a privileged source, the accounts of residents of the neighborhood. These subjects' accounts, are expressed in two books on the region's constitutional movement, one written by a resident, and another, a work produced by researchers, residents and the local government of Victoria. It also highlights the narratives of a cook and a general services assistant, professionals of the institution being investigated. The sources are analyzed as witness accounts providing remnants of knowledge and therefore comparative data. What it seeks to understand are the "practical strategies" and "tactics" employed by the subjects in these popular movements: the housing organizations; the educational institutions; to reflect on these experiences to assist those that remain in CMEI teaching children currently.

Keywords: Social Movements. Schooling. Narratives.

\section{Introdução}

Este estudo parte das discussões elucidadas na pesquisa de Nunes (2007), ${ }^{1}$ que aborda a escolarização da Educação Física na Educação Infantil, no âmbito da Secretaria Municipal de Ensino de Vitória/ES (SEME/PMV), em atenção às modificações delineadas pelos diferentes formatos dos cargos apresentados pelos concursos públicos entre 1991 e 2007. Dentre os 43 Centros Municipais de Educação Infantil (CMEIs), selecionamos como lócus o CMEI da Amizade, nome fictício dado a uma unidade localizada no bairro São Pedro I, para perceber singularidades e continuidades desse movimento.

Orientados pelo "paradigma indiciário" de Ginzburg (1989), considerando pistas e sinais pormenorizados ou negligenciados, buscamos uma instituição que tivesse acompanhado os diferentes contornos da Educação Física e se interessado pelas discussões e produções a respeito do Projeto Político-Pedagógico e do Currículo. A pesquisa de campo permeou o período compreendido entre os meses de março a setembro de 2007 , especialmente entre as $7 \mathrm{~h}$ e as $12 \mathrm{~h}$, totalizando 69 encontros.

No decorrer da investigação, percebemos que a instituição pesquisada traz indícios de acompanhar o movimento de escolarização do bairro, a partir da constituição da região, nos anos 1970. Para investigar as 
relações entre os moradores e as instituições educativas, priorizamos como fontes documentos da PMV, livros e narrativas de moradoras do bairro que participaram dessa constituição e permanecem no trabalho com a educação de crianças.

Assim, a escrita desta versão confere centralidade às publicações de Graça Andreatta (1987; 2003). Trata-se de uma ex-moradora do bairro que, com o marido, Ruy, constitui-se como referência na comunidade, tanto na organização do processo de ocupação do manguezal que deu origem a região quanto na mobilização do movimento comunitário de São Pedro. A primeira publicação refere-se a um relato, com aspecto de denúncia, da ocupação, a partir de sua história de vida.

A segunda obra é um livro de poesias que se vale de alguns episódios do bairro como inspiração. A produção, organizada por Gurgel e Pessali (2004), também é utilizada como fonte, uma vez que congrega a participação de profissionais da PMV, de pesquisadores, jornalistas e moradores de São Pedro para retratar aspectos históricos, políticos, econômicos, sociais e organizacionais da constituição da região. Revela-se importante por ampliar a compreensão do objeto pesquisado e por reunir análises de diferentes aspectos desse contexto.

No que se refere aos sujeitos que praticam o lugar pesquisado, privilegiamos o relato de uma assistente de serviços gerais (ASG) que acompanha a instituição antes do processo de municipalização (1984), e de uma cozinheira que problematiza a autoria da fundação das instituições de atendimento às crianças pequenas.

As fontes são analisadas como "testemunhos" (BLOCH, 2001), como conhecimento lacunar, através de "vestígios", como possibilidade de buscar singularidades e entrecruzamentos na produção de sentidos e significados que envolvem o processo de escolarização da região. Nesse caso, pistas, por vezes pormenorizadas (GINZBURG, 1989), serão consideradas junto às narrativas na produção de uma versão que se interessa pelo movimento de escolarização, pouco explorado pelas produções que analisam o bairro.

Ao exercer um "mergulho" no universo pesquisado, identificamos que, no ano de 2007, o bairro São Pedro I completava 30 anos, em4 de setembro (ANDREATTA, 1987). Seu primeiro espaço destinado à infância completava 29 anos, um dado marginal revelador de que a história da escolarização e da região se complementam. No entanto, o bairro e 
suas instituições escolares sofreram certas limitações em seu processo de constituição, visto que a região carecia de necessidades muito mais basilares se comparadas à de escolarização. A partir disso, conhecer o contexto histórico da região e as práticas tecidas cotidianamente em um CMEI nos estimula a problematizar algumas questões: Em que medida as experiências dos movimentos sociais e de escolarização influenciaram as práticas escolares? De que maneira as narrativas dos sujeitos que praticam essa história nos ajudam a recuperar outros sentidos da experiência docente?

Para, ao modo de Benjamim (1994), "escovar a história a contrapelo", revirá-la, varrê-la ao contrário, serão utilizados estudos que privilegiam a inserção das leituras, das narrativas, das práticas e dos conhecimentos dos moradores e profissionais da região, a fim de problematizar os silenciamentos e o desperdício de suas experiências. Mostram-se relevantes a compreensão de Certeau (1994) a respeito dos sujeitos como "praticantes" bem como a relação entre as noções de "estratégia" e "tática". Também as discussões de Santos $(1985 ; 2004)$ sobre "movimentos heterológicos" inspirados por exercícios da hermenêutica.

\section{Processo de constituição do bairro São Pedro: com os pés na lama e no lixo}

"A incompreensão do presente nasce fatalmente da ignorância do passado. Mas talvez não seja menos vão esgotar-se em compreender o passado se nada se sabe do presente" (BLOCH, 2001, p. 65).

Para acrescentar outras histórias àquela tradicionalmente narrada sobre a ocupação que originou os bairros da região São Pedro, valemonos dos estudos de Bloch (2001), a fim de compreender como a escolarização da região é influenciada pelo seu processo de constituição, numa relação em que o conhecimento do passado e do presente estão condicionados. Nesse caso, estamos assumindo, como Bloch (2001), que a ignorância do passado não se limita a prejudicar o conhecimento do presente; compromete, no presente, a própria ação.

Os estudos de Santos $(1985 ; 2004)$ a respeito de "movimentos heterológicos" são utilizados para ampliar as possibilidades de discussão. 
Trata-se de um procedimento que valoriza diálogos heterogêneos e plurais pela interpretação de diferentes formas de conhecimento: científicos, escolares, comunitários, políticos, ecológicos, culturais, econômicos, religiosos, entre outros. Para o autor, a relação entre modos diferentes de viver e conhecer pode originar uma nova racionalidade que, pela prudência, qualifique o conhecimento e se traduza em sabedoria de vida. Assim, a possibilidade de atribuir sentidos a diferentes conhecimentos, ressignificando-os em sua complexidade, sem hierarquizá-los, depende do potencial de articulação com os saberes considerados relevantes para determinado grupo social.

Numa relação de disputa entre saberes, fazeres e poderes, consideramos os sujeitos da região como "praticantes" (CERTEAU, 1994), uma vez que não assumimos que eles são determinados e ou que se deixam aprisionar por instâncias de maiores domínios, como o poder público. Sem negar essa influência, consideramos que os sujeitos agem nas entrelinhas, nas fissuras, nas brechas permitidas pelas regras desse jogo de poder. Numa relação que considera "estratégias" e "táticas", estamos atentos aos modos "táticos" na constituição da região São Pedro, nos movimentos de escolarização, nos modos de praticar a vida.

Nesse caso, a teorização de Certeau (1994) aponta que a "estratégia" refere-se ao instituído, às regras e leis criadas, às determinações, por exemplo, do poder público, que, na década de 1970, pretendia abafar as organizações populares. Em relação, e não em oposição, são criados "usos táticos", que se desviam, de modo sorrateiro, dessas determinações, que se utilizam de suas brechas para criar novos modos de vivê-las. De acordo com Certeau (1994, p. 101): “[...] a tática é determinada pela 'ausência de poder' assim como a estratégia é organizada pelo postulado de um poder". Nessa relação, nosso esforço está em compreender os sujeitos como "praticantes" que, enredados por diversas relações, assimétricas e heterárquicas, entre elas, as ações do tipo "tática", podem tensionar modificações do tipo "estratégica".

Desse modo, consideramos que se as regras são organizadas "estrategicamente", as "táticas" representam a capacidade de desviar, contornar ou burlar. Os moradores dessa região, para além de consumir ordens de modo obediente, instituem usos diferenciados de produtos, regras e "estratégias" impostas; tensionam outras possibilidades para sua vida e praticam modos impensados de ser e estar no mundo. 
Considerar a oportunidade de construir outros conhecimentos e versões praticadas pelos sujeitos anônimos do cotidiano, que possam ser invisibilizados pelo discurso oficial, nos leva a compreender como as histórias dos bairros São Pedro I e Ilha das Caieiras revelam-se imbricadas. Em nossas fontes, a Ilha das Caieiras ${ }^{2}$ aparece como uma pequena comunidade de pescadores habitada desde o século XIX. O local funcionava como ponto intermediário entre a boca do Rio Santa Maria e os armazéns do Porto de Vitória. "Essa ligação aumentou a população da ilha com famílias que trocavam a roça, empobrecida pela queda do preço do café, pela cidade, e encontravam na ilha um ambiente típico de interior" (GURGEL; PESSALI, 2004, p. 24).

Além do significativo aumento populacional da Grande Vitória ${ }^{3}$ registrado pelo Instituto Brasileiro de Geografia e Estatística (IBGE) (de 200 mil habitantes, em 1960, a 1 milhão e 300 mil, em 2000, tendo Vitória mais de 300 mil habitantes, em 2007), o rápido crescimento da região São Pedro foi influenciado pela transferência de algumas famílias que ocupavam o bairro Miramar, que foi desabitado para a construção da rodoviária. Além das 72 casas construídas na rodovia Serafim Derenzi para indenizar essas famílias, o manguezal foi ocupado por outras de modo tático, imprevisto. Esse movimento, ao percorrer a região ao longo da rodovia, originou os bairros São Pedro I, II, III, IV, V e VI, também conhecidos como região São Pedro (GURGEL; PESSALI, 2004; DIAS, 2001).

A ocupação foi permeada por um processo de derrubada e queima de moradias pela polícia e outras autoridades. A ex-moradora desabafa: "O hoje São Pedro seria área burguesa. E nós ocupamos. Temos que ser perseguidos, é claro" (ANDREATTA, 1987, p. 54). Os residentes foram vítimas do descaso, do desrespeito, da insegurança, da precária estrutura e das disputas pelo assentamento, às vezes fazendo vítimas fatais. Alguns "heróis", falecidos ou não, bem como acontecimentos e datas importantes foram imortalizados, emprestando seus nomes para algumas ruas, tais como: Rua da Libertação, Rua da Esperança, Rua da Igualdade, Rua do Acordo, Rua da Dificuldade, Rua do Amor, Rua Dr. José Geraldo Bermudes (presta homenagem ao juiz que assinou a lei que concedia a posse do mangue até essa rua), o Beco 26 de Dezembro e a Avenida 4 de Setembro.

A falta de experiência da comunidade dificultou, inicialmente, sua sistematização e seu planejamento. Com "táticas" mais organizadas, 
formaram o Movimento Comunitário do bairro, operando as "artes do fraco", golpe a golpe, na construção de moradias, na numeração dos barracos, na abertura das ruas e na busca de infraestrutura (Figura 1).

Mil maneiras de jogar/desfazer o jogo do outro, ou seja, o espaço instituído por outros, caracterizam a atividade, sutil, tenaz, resistente, de grupos que, por não ter um próprio, devem desembaraçar-se em uma rede de forças e de representações estabelecidas. Tem que 'fazer com'. Nesses estratagemas de combatentes existe uma arte dos golpes, dos lances, um prazer em alterar as regras de espaço opressor. Destreza tática e alegria de uma tenacidade (CERTEAU, 1994, p. 79).

\section{FIGURA 1}

Pedras usadas para a contenção da maré.

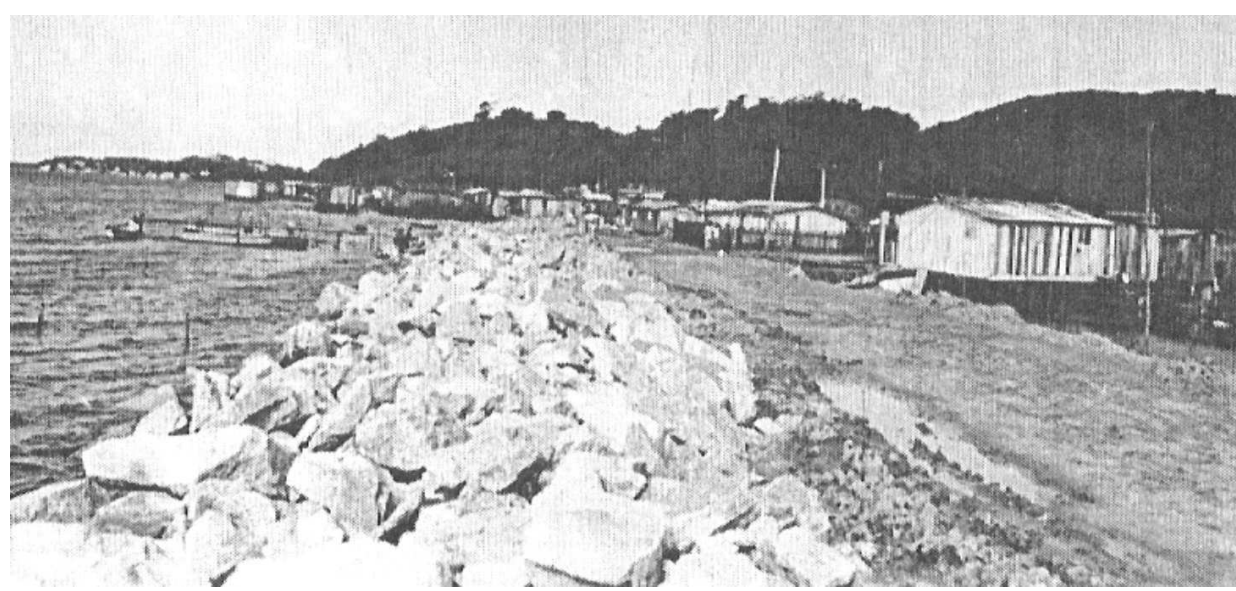

FONTE: Gurgel e Pessali $(2004$, p. 131)

As redes de solidariedade da população, que se constituíam por necessidades econômicas, começavam a modelar-se de maneira mais politizada por meio de uma série de movimentos contra-hegemônicos. Como a política hegemônica pretendia pulverizar os movimentos populares, a ocupação não contou com o apoio do poder público. Entretanto, o Movimento Comunitário e as Comunidades Eclesiais de Base (CEBs) da Igreja Católica constituíram-se numa organização religiosa e social (ANDREATTA, 1987).

Trata-se de "maneiras de utilizar" os sistemas impostos; as diversas manobras entre forças desiguais e com auxílio de poderes utópicos; a "astúcia" dos moradores no modo de driblar os termos do contrato social (CERTEAU, 1994). Essa disposição demonstra que grupos sociais com finalidades diferentes podem se articular num movimento contra-hege- 
mônico, que amplia o potencial de ambos por meio de ações criativas e próprias do contexto onde se inserem (SANTOS, 2004).

A solução para o aterro do manguezal foi a utilização do lixo, em 1977, que contribuiu para uma mudança no quadro profissional, com a formação dos catadores que vendiam lenha, plástico, vidro, papel e latas. Disputavam o espaço e o lixo com moscas, ratos, baratas, urubus, porcos e cães (Figura 2), visto que "[...] o lixo representava alimentação, trabalho (comércio de restos) e moradia (aterro sobre o qual eram construídas as casas)" (GURGEL; PESSALI, 2004, p. 37-38).

\section{FIGURA 2}

Moradores em meio ao revoo dos urubus.

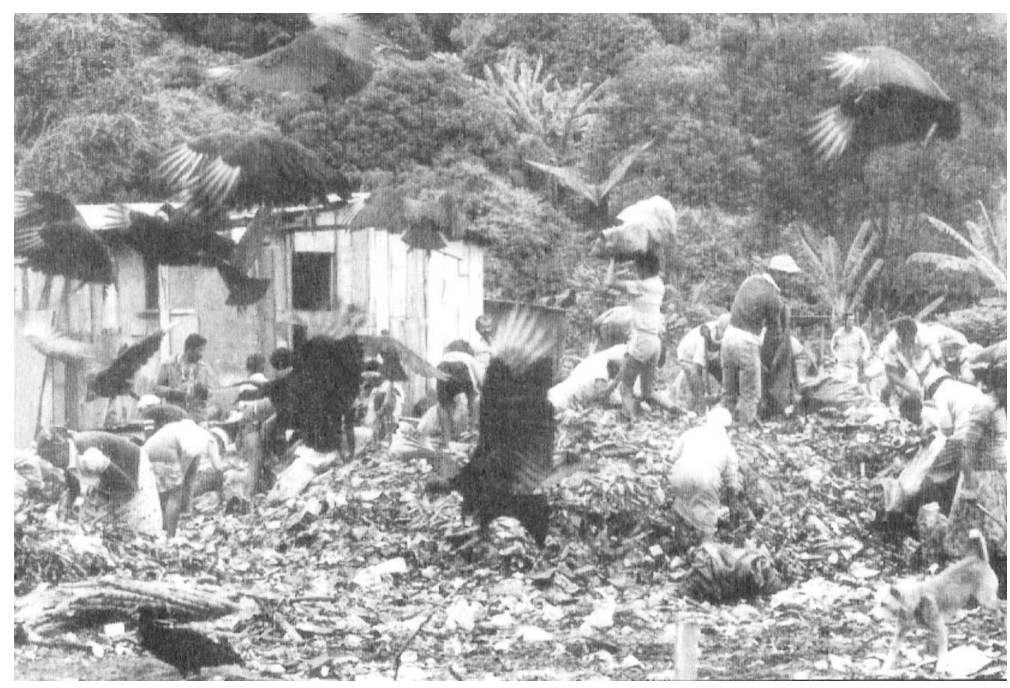

FONTE: Dias (2001, p. 22)

Em um dos seus poemas, Andreatta (2003) retrata a questão do lixo vivenciada no bairro:

No lixo tem bicho

Mas tem gente com fome

Catando, colhendo, vendendo,

Morrendo, no lixo

Do bicho, do homem perfumado,

Que fuma cachimbo importado

Com dinheiro tirado do lixo

Com bicho

Que o povo procura

Pra tentar comer

Porque emprego não tem, aumento não vem 
E, no lixo, mesmo com bicho,

Tem lata, plástico, papel...

Tem até panela que jogam fora,

E vidros com resto de mel [...]

No lixo tem noitadas de lua cheia,

Porcos de arroba e meia, urubus de todas as qualidades:

- "Abutres" humanos em busca de novidades,

De votos, misérias

- E urubus de verdade [...].

(No lixo, ANDREATTA, 2003)

Com a presença de atravessadores que lucravam e exploravam os moradores, a comunidade organizou-se na criação da Associação Cooperativa dos Catadores de Vitória "Homero Mafra" (ACCATAV HOMERO MAFRA), que recebe o nome do juiz que garantiu a reintegração de posse do lixo (ANDREATTA, 1987). Em 1987, a Prefeitura organizou-se na urbanização de alguns bairros da região São Pedro. Em 1990, foi inaugurada a Usina de Lixo de Vitória, em São Pedro VI, que emprega aproximadamente 300 trabalhadores e representa "[...] um ganho ambiental e social, pois acaba com o depósito de lixo do manguezal e com a convivência subumana de centenas de pessoas no lixão" (DIAS, 2001, p. 25).

Andreatta (1987) descreve que o bairro foi "ocupado" de maneira desordenada pelo povo, mas a região também foi "invadida" de maneira planejada por um movimento que ambicionava desestruturar a organização da comunidade que se formava num período historicamente desfavorável às organizações dos movimentos sociais. Durante o ano 1983, diversas formas de manipulação política contribuíram para a desarticulação do Movimento Comunitário, sendo as mais expressivas relacionadas com o filme Lugar de toda pobreza, com a Cruz Vermelha e com a Escola Grito do Povo.

A produção do documentário Lugar de toda pobreza $a^{4}$ representou uma importante denúncia de condições desumanas de vida, sem qualquer apoio do governo, no período da ditadura. Com a repercussão das imagens da região, muitas iniciativas mobilizaram doações em dinheiro, em cestas básicas e roupas pela Cruz Vermelha, todas intermediadas pela Prefeitura. Os moradores puderam contar com o apoio financeiro do Papa, em sua visita à região, em 1991, além da movimentação de outras iniciativas. 
Para Andreatta (1987), o documentário não refletiu a organização da comunidade e os avanços obtidos, apenas cenas de fome e de miséria. As doações levaram a uma disputa acirrada da comunidade e à consequente desestruturação do movimento popular. A questão não era desmerecer as doações, mas permitir que o povo continuasse se articulando para que as autoridades trabalhassem na construção de condições básicas de sobrevivência, dever do Estado e direito de todo cidadão.

Com relação à Escola Grito do Povo, construída e organizada pela comunidade, a autora descreve os descompassos causados pela centralização da escola, quando foi integrada à Rede Municipal de Ensino de Vitória.

Atualmente, os bairros da região São Pedro são urbanizados, contam com escolas, comércio e serviços, igrejas, quadras poliesportivas, praças, restaurantes, tendo sua história amplamente valorizada pelos moradores, pelas escolas e pelos movimentos comunitários. Conta com atendimento especializado ${ }^{5}$, com diversos serviços para a criança, a mulher, a família, as doenças epidemiológicas, as zoonoses, além de tratamentos preventivos. Os moradores recebem, ainda, apoio de alunos e funcionários de diversas instituições, em especial da Universidade Federal do Espírito Santo (UFES) e das Faculdades Associadas do Espírito Santo (Faesa), tanto na construção quanto na execução de inúmeros projetos (GURGEL; PESSALI, 2004).

Dados do Plano de Ação de 2007 do CMEI pesquisado revelam “indícios" de mudanças em relação à escolaridade, à profissão, à renda familiar e à religiosidade. Registram aumento significativo no tempo de estudo e no nível de escolaridade das famílias, variando entre o Ensino Fundamental, o Médio e o Superior. Quanto às atividades profissionais, ampliaram-se da pesca e de serviços informais para outras profissões, como: auxiliar de serviços gerais, diarista, vendedor/a, policial militar, cozinheira, cabeleireira, comerciante, costureira, atendente, professor/a e profissionais da área da saúde. A mudança no nível de escolaridade e na profissão projetou alteração na renda das famílias, que aumentou, em média, para a faixa de dois a três salários mínimos. A opção religiosa, antes predominantemente católica, apresenta-se agora também evangélica.

Uma das assistentes de serviços gerais (ASG) da instituição pesquisada narra parte do desdobramento de uma história que se confunde com a sua. Assim como nos diz Benjamin (1993), observamos que a ati- 
vidade narrativa permite que, pelas suas experiências, ela também se reconheça nesse tempo e espaço. Para além de mera informante de nossa pesquisa, suas narrativas possibilitam contemplar a intensidade do vivido, de histórias que fazem parte do seu presente e do seu futuro.

— foi uma história muito linda, eu participei dela [...]. Nós temos uma parte que não se deu muito bem, mas é aquilo, cada um toma o rumo que quer [...]. Lindo é quem estudou ali está onde está hoje. Nós temos jovens que estudaram ali, graças a Deus, louvado seja Deus, formados. Daquele tempo, que a gente conseguiu que funcionasse o primeiro ano, já está tudo formado. Nós já temos pediatra, dentista, temos vários pedagogos, professores [...] E esse bairro aqui, naquela época e até hoje, é um bairro caloroso. [...] Essa camarada aqui, por exemplo, [a cozinheira] mora aqui na Ilha. Ela de vez em quando, pega uma sacolada de peixe, dá pra mim, ou dá pra fulano, sem questão nenhuma. Aí tem uma outra amiga que é professora, e o marido pesca, que dá uma enxurrada de peixe. Olha, sem aumentar, uns 3 ou 4 quilos de peixe pra cada um. Época de torta aqui, você com dinheiro ou sem dinheiro, você come, todo mundo come. Um vai na casa do vizinho. E hora que morreu um que não tem parente, a gente que paga. (ASG).

Escolarização. Urbanização. Solidariedade. Profissionalização. Violência. Religião. Tudo é tecido nessa rede de histórias e memórias. Uma multiplicidade de conhecimentos obtidos através de vestígios que são produzidos a cada dia, de testemunhos quase infinitos, uma vez que "tudo que o homem diz ou escreve, tudo que fabrica, tudo que toca pode e deve informar sobre ele" (BLOCH, 2001, p. 79).

\section{FIGURA 3}

Espaços públicos construídos em 2007: praça, academia popular, quadra poliesportiva

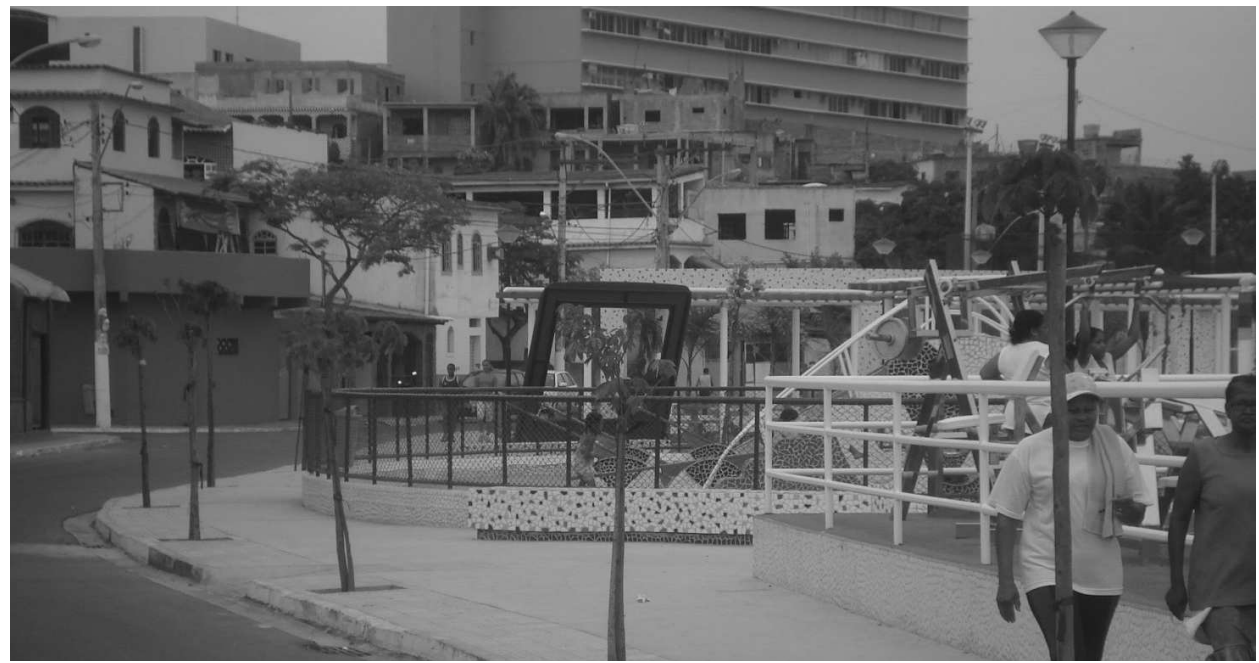

Educação em Revista | Belo Horizonte | v.28 | n.01 | p.109-130 | mar. 2012 
$\mathrm{Na}$ região que era conhecida como lugar de toda pobreza ainda permanecem os resquícios de violência por assaltos, drogas e assassinatos. Entretanto, os bairros São Pedro e a Ilha das Caieiras também são conhecidos e apreciados pelas suas iguarias. O trabalho das mulheres da região - na culinária, utilizando peixes e mariscos, na confecção das panelas de barro típicas da moqueca capixaba, no desfiar do siri -, além dos atrativos naturais, é foco da atenção de turistas e objeto de valorização dos moradores da região.

Embora, nas últimas gestões, a relação dos moradores do bairro com o poder público tenha trazido benefícios para a população quanto à estrutura física, de saúde, lazer e educação, a constituição de São Pedro foi permeada por inúmeras "táticas" de resistência, "astúcias" sutis e inventivas de sobrevivência na ocupação do mangue, no delineamento de infraestrutura e na construção de espaços educativos. Trata-se, ao modo de Certeau (1994), de uma "arte de fazer", que está ligada à "arte de viver" dos moradores do bairro.

\section{As crianças, as escolas e o grito do povo}

Essa creche foi a primeira... a primeira de São Pedro! Porque se botar Ilha das Caieiras, é o Magnólia. Ela foi a primeira creche em Vitória [...]. O Magnólia foi a primeira creche de tudo. Dali eu posso falar porque eu estudei ali, meus filhos estudaram. Antigamente era Creche da Ilha. Minha mãe fundou a creche, trabalhou de cozinheira lá. O Cantinho da Amizade foi assim. Começou com a escola O Grito do Povo. Quando ele foi para a escola nova, ficou aquele espaço lá. E a creche ainda não tinha lugar. (COZINHEIRA)

Ao atribuir a origem de uma instituição na Ilha das Caieiras como a primeira no atendimento das crianças menores de seis anos, tanto da região pesquisada quanto do município de Vitória, o relato de uma cozinheira do CMEI da Amizade revirou nossa versão dessa história. Sua narrativa fez-nos perceber que outras podem ser escritas e recriadas sobre a origem das instituições escolares da região. Em todas as outras fontes, documentos e entrevistas, os dados evidenciavam a origem da escolarização da região por organizações no bairro São Pedro, e não no bairro Ilha das Caieiras, o que demonstra que essas histórias são permeadas por continuidades, tensões e contradições. 
Ao garimpar as fontes de que dispúnhamos, observamos que a primeira referência de um espaço educativo dizia respeito a uma iniciativa informal que se constituiu na adaptação de um cômodo de madeira, em 1977, no "[...] barraquinho do Toninho Tonini, com luz de velas. Todo mundo dava aula para todo mundo" (ANDREATTA, 1987, p. 20). Com o rápido aumento de dez para cinquenta alunos, a comunidade mobilizouse na organização de uma sala reservada para as aulas na sede comunitária. Em 1978, formou-se a primeira turma de adultos em Educação Integrada, pela noite, e uma turma de pré-escola, durante o dia (ANDREATTA, 1987). Um levantamento censitário identificou 553 crianças em idade escolar que estavam fora da escola, o que foi determinante para a mobilização da população, com apoio da Secretaria de Ação Social, na construção da primeira instituição educativa, conhecida como Grito do Povo (Figura 4).

\section{FIGURA 4}

Primeiras instalações da escola Grito do Povo. Fonte: Andreatta (1987, p. 151)

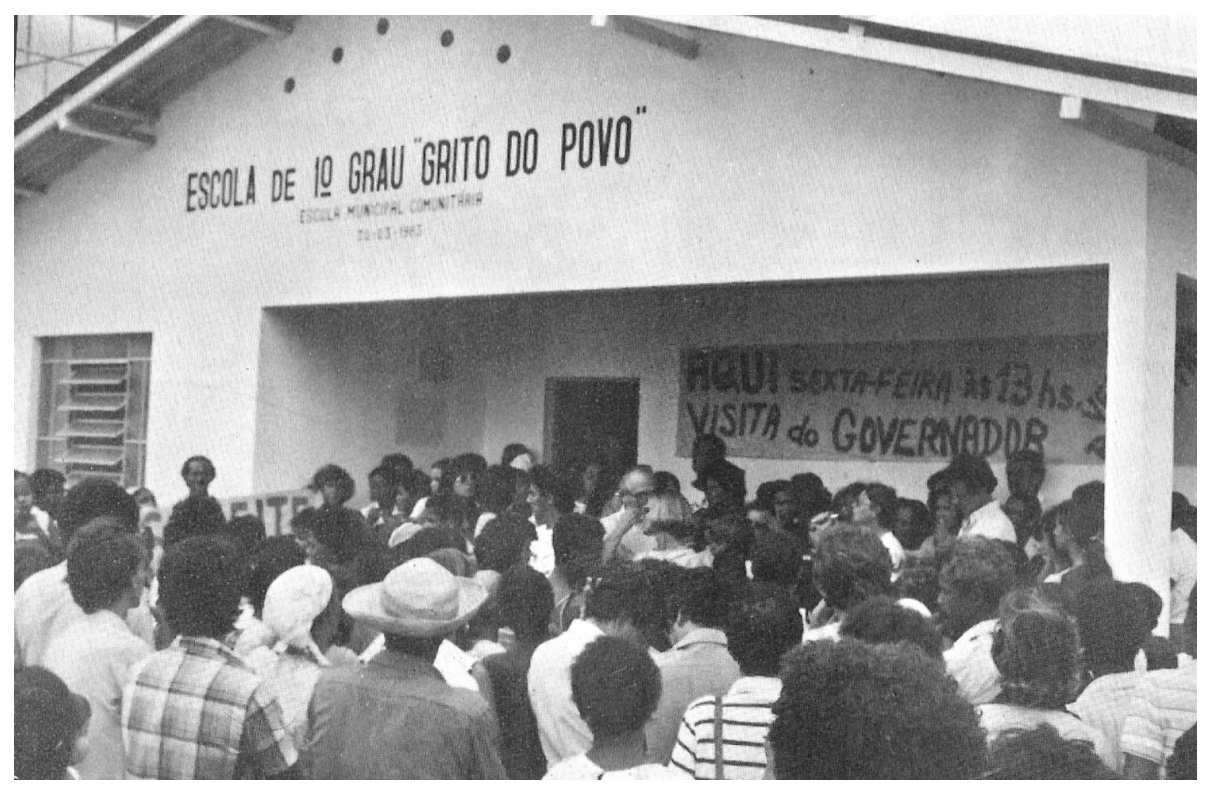

À medida que a necessidade de uma instituição mostrava-se cada vez mais intensa, a solidariedade da população também aumentava. Articulavam suas "artes de fazer" no trabalho voluntário: ministravam aula, confeccionavam carteiras, coletavam material didático, pedagógico, higiênico, além dos alimentos.

Segundo Andreatta (1987), a escola era organizada de acordo com a necessidade da comunidade, que formou uma Comissão de 
Educação para estudar normas pedagógicas e apresentá-las no debate comunitário. O método de Paulo Freire era estudado e adaptado, respeitando a realidade social. $\mathrm{O}$ grupo de professores reunia-se aos sábados para planejamento das ações e mobilização da comunidade. A experiência pedagógica que rompia com a dicotomia entre o conhecimento científico e o senso comum, como salientam os estudos de Santos (1989), despertou o interesse da rede pública e privada, dos professores e alunos da UFES. Também fortaleceu a participação feminina e contribuiu para a formação do Movimento das Mulheres Unidas de São Pedro (Musp).

Desde que começou a funcionar, nós fomos os primeiros funcionários. Nós começamos a trabalhar como voluntários (ASG).

Grito do Povo é porque foi conseguido no grito (COZINHEIRA).

Foi isso mesmo. Nós fizemos quantas passeatas saindo de São Pedro e indo pra prefeitura a pé?! [E diziam:] olha, o pessoal de São Pedro ta vindo aí (ASG).

Com panelas, com tudo (COZINHEIRA).

Todo mundo aprendeu a se movimentar [...]. E ainda tem uma outra questão, o grupo de Mulheres Unidas de São Pedro. Esse grupo foi, assim, a base para essa comunidade. Porque, vamos falar a verdade, eu falo com você que eu estudei pouco. Quantos naquela época, não tinham formação nenhuma, e a pessoa que não tem muita informação é tratada como ignorante. Então [esse grupo representou uma oportunidade para] incentivar os direitos da mulher, não é o direito de briga, de se comportar diferente, não, é o direito de cidadania. E Graça colocava isso para a gente, que nós temos que estar, não é nem atrás do marido e nem na frente do marido, e sim do lado do marido. E do lado das coisas que nos levam a gerar fonte de renda para a mulher (ASG).

Em março de 1984, a escola Grito do Povo foi municipalizada e contou com novas instalações. Os moradores organizaram uma inauguração solene para a entrega das chaves, com a presença do prefeito. A escola já possuía 150 crianças na creche, 200 crianças na pré-escola, 1.500 alunos no $1^{\circ}$ grau (atual Ensino Fundamental) e inúmeros moradores que se fizeram profissionais para trabalhar voluntariamente.

Apesar das promessas da PMV referentes ao apoio para a estrutura física, à contratação dos colaboradores, ao respeito com relação ao projeto pedagógico e ao nome da escola, percebemos uma constante ten- 
são entre a organização popular e o poder público com relação às operações "estratégicas" que visavam a controlar e organizar o espaço social (CERTEAU, 1994; JOSGRILBERG, 2005). Houve uma ruptura entre o discurso e a prática, e nenhum dos compromissos foi efetivado à risca (ANDREATTA, 1987; GURGEL; PESSALI, 2004). Com o auxílio de Josgrilberg (2005, p. 27), compreendemos que

Poder e sujeitos se relacionam dialeticamente. Se os sujeitos estiverem fora da esfera de poder, se estiverem no limiar da ilegalidade, a organização do poder será, de uma forma ou de outra, reorganizada a fim de manter sua eficácia ou, então, haveria um rompimento com o poder que a organiza.

De modo estratégico, a fim de manter a legalidade e a eficácia do controle, foram garantidos sessenta funcionários, mas não se consolidou o contrato de todos, especialmente dos primeiros colaboradores (ANDREATTA, 1987). Quanto à estrutura física, foram planejadas instalações para uma creche, mas o prazo foi comprometido pelo projeto Promorar (GURGEL; PESSALI, 2004). ${ }^{6}$ O nome da escola foi modificado devido a uma medida da PMV que estabelecia que todas as instituições de ensino deveriam ser registradas com o nome de um famoso educador. No caso dessa escola, prestou-se uma homenagem ao ex-governador do Estado.

De acordo com os documentos do CMEI e com as entrevistas, quando a escola Grito do Povo se organizou no novo prédio, suas antigas instalações cederam lugar à creche Cantinho da Amizade, que ali funcionou no período compreendido entre 1984 e 2005. Trata-se da instituição pesquisada neste estudo, como confirmou uma das assistentes de serviços gerais:

$\mathrm{Na}$ verdade, essa creche foi o seguinte. Começou uma escola lá pertinho do movimento comunitário que era na capelinha. A comunidade: "Ah, nós podia botar um nome aqui [...]". Foi posto em votação que seria Grito do Povo. E, nesse Grito do Povo, a Prefeitura tava construindo essa escolinha, que foi a primeira escola antes do FLA foi ela [...]. Aquela escolinha lá, veio pra ali [para o antigo prédio da EMEF FLA] e ficou sendo Grito do Povo. Mas só que tava pegando aquelas crianças que já tinha de seis anos em diante, sete anos, que era o primeiro ano. E a gente viu muita dificuldade daquelas mães que já tinham os menores, que era de um ano [...]. A ideia inicial foi pra escola [...]. Então, quando a escola passar pro FLA, aqui vai ser a creche (ASG). 
Para Andreatta (1987), a partir de janeiro de 1984, quando a escola passa a ser incorporada à Rede Municipal de Ensino de Vitória, perdeu-se a administração pela comunidade, além das características constitutivas da escola: "Naquele dia, nós enterrávamos a filosofia da escola, o sonho de ter uma escola administrada pela comunidade, a partir de nossa realidade universal... Daí em diante, foram rasgados todos os papéis que contavam a história do GRITO DESTE POVO" (ANDREATTA, 1987, p. 94). Assim como a escola, a creche recebe outro nome. De Cantinho da Amizade passa a ser conhecida como CMEI da Amizade, no ano 1993. ${ }^{7}$

Realmente, não localizamos outros documentos que dessem visibilidade ao movimento de escolarização da região, assim como nos alerta a antiga moradora. Contudo, Dias (2001) já contabilizava, há quase uma década na região, seis movimentos comunitários e 26 associações de classe (como a Mulheres Unidas de São Pedro - Musp, os Idosos de Resistência, os Idosos de São Pedro I e do Centro de Treinamento). Esses novos espaços, organizados taticamente, referem-se a lugares praticados que operam um movimento que procura fugir às operações de poder que tentam controlar o espaço social (CERTEAU, 1994; JOSGRILBERG, 2005).

No momento, a Região São Pedro conta com sete Escolas Municipais de Ensino Fundamental (EMEFs) e cinco Centros Municipais de Educação Infantil (CMEIs), ${ }^{8}$ que frequentemente têm valorizado e reescrito essas e outras histórias em seus projetos pedagógicos, utilizando documentos, fotos pessoais, entrevistas com moradores e outras fontes, a fim de que também percebam rupturas e continuidades no processo de constituição da região. Com os projetos desenvolvidos com a participação dos/as alunos/as e das famílias, compreendemos que os aspectos da cultura ordinária da região, que possui um histórico de reivindicações, conquistas e solidariedade, influenciam tanto os alunos quanto a proposta pedagógica das instituições educativas locais.

O Plano de Ação de $2007^{9}$ do CMEI da Amizade revela que as famílias participam das decisões e dos encaminhamentos da instituição: "[...] sempre que solicitada a comunidade tem boa participação buscando alternativas para a melhoria da escola num todo". Em entrevista realizada no dia 25 de junho de 2007 com a diretora do CMEI da Amizade, podemos confirmar essas informações: 
O pai quando chegar tem prioridade no atendimento, porque é a na hora que ele está podendo vir [...]. Porque eu preciso desse pai sabendo o que acontece no espaço da escola, porque, na hora que eu pedir a colaboração dele, ele precisa saber por que ele está colaborando.

O registro das mudanças, no que tange a estrutura física e ao pessoal conquistados pelos sujeitos dessa instituição, consiste num dado importante. De uma sala do movimento comunitário ao antigo prédio da EMEF Francisco Lacerda de Aguiar, o CMEI da Amizade, atualmente, conta com estrutura previamente planejada para o trabalho com crianças pequenas. A mudança para as instalações atuais, que ocupam parte privilegiada de um quarteirão, ocorreu em 2006.

De acordo com a Planta Baixa do seu Projeto Arquitetônico, o CMEI compreende aproximadamente $2.000 \mathrm{~m}^{2}$, sendo $1.378 \mathrm{~m}^{2}$ de área construída. Isso significa que a instituição reserva espaço livre de aproximadamente $600 \mathrm{~m}^{2}$ para as crianças e as profissionais, especialmente nos pátios. Ao todo, identificamos doze salas de aula, quatro salas para a organização pedagógica dos professores, uma sala de vídeo e biblioteca, um laboratório de informática para crianças, oito banheiros e amplo espaço para preparo e degustação dos alimentos.

A instituição conta com doze turmas em cada turno para atender, aproximadamente, 250 crianças entre seis meses e seis anos de idade. Em 2007, o CMEI apresentava um quadro com 46 profissionais no turno matutino, responsáveis pelo cuidado e pela educação de suas crianças: uma diretora, duas pedagogas, uma assistente administrativa, dezesseis professoras regentes de sala, quatro professoras dinamizadoras, com formação em Educação Física, duas estagiárias para o Maternal, três auxiliares de berçarista, sete assistentes de serviços gerais, cinco cozinheiras, quatro agentes de segurança, além de uma profissional especialista no trabalho com crianças que apresentam necessidades educativas especiais.

Das dezesseis professoras regentes no turno matutino, seis são moradoras do bairro e possuem mais de dezesseis anos de experiência nesse CMEI, algumas tendo trabalhado, inicialmente, como ASG. Todas as ASGs e cozinheiras são moradoras do bairro. Dentre elas, três ASGs possuem 22 anos de trabalho com crianças pequenas e foram efetivadas como celetistas no processo de municipalização da instituição. A profissional entrevistada nesta pesquisa relata que acompanha o CMEI desde as suas primeiras instalações, quando se chamava Cantinho da Amizade. Ela 
nos conta que o trabalho que realizava com as crianças era pouco diretivo, pois preferia deixá-las brincando: "Quando chegaram as novas professoras, as crianças preferiram ficar com a gente".

Na prática, o grande número de profissionais dessa instituição residentes no bairro representa maior envolvimento com as crianças e com suas famílias, visto que as pessoas são conhecidas pela comunidade. A maioria das profissionais da instituição que residem em São Pedro valoriza as conquistas da instituição e se envolve com o trabalho pedagógico, uma vez que esses lugares marcaram suas histórias como alunas, filhas de funcionárias, mães de alunos/as, tias, vizinhas, diversas relações referenciadas por outros espaços para além dos escolares. É com a cozinheira que conhecemos algumas experiências da infância, de criança que se constitui na região São Pedro:

Eu era criança, eu me lembro da colônia de férias, era muito bom. Eu queria que voltasse, e hoje em dia não tem. $\mathrm{Na}$ época do [CMEI] Magnólia, que eu era criança, e estudava ali, o mês de janeiro era o mês todinho de férias. A gente ficava na colônia de férias (COZINHEIRA).

Só com atividades recreativas? (PESQUISADORA).

Só, e almoçava tudo lá, sabe? Era assim: tinha horário de 7 a 1 e de 1 às 5 [...]. A gente ficava livre, brincando no balanço. Só no balançinho. Mas na creche, eu lembro que tinha aquela pedrona, aquela escola velhinha, eu ficava o dia todo. Era o dia todo, toda criança. Era criança de 1 ano até 6 anos, era o dia todo. Eu enjoei de ficar na escola [...]. Eu fugia, eu tinha 6 anos e já pulava o muro (COZINHEIRA).

Independentemente da qualidade do atendimento às crianças pequenas, da sistematização dos conhecimentos e das experiências propostas, a permanência em tempo integral das crianças nas instituições educativas foi problematizada por essa cozinheira como algo sacrificante, maçante, desgastante, tendo a fuga como uma das alternativas. No Ensino Fundamental, já reconhecia o lugar escolar, bem como comportamentos, ações e relações que lhe dizem respeito. Que experiências nossas crianças têm vivenciado na Educação Infantil atualmente, nessas e em outras instituições? O que dizem sobre seus tempos, espaços, sujeitos, experiências, odores, sabores e lembranças que marcaram sua história nesses lugares? 
Em 2007, ano em que a pesquisa de campo foi realizada, as experiências da comunidade escolar foram amplamente valorizadas na constituição do Projeto Político-Pedagógico (PPP) do CMEI da Amizade. Essa construção foi organizada a partir de um relato de experiências vividas com as professoras, as crianças e as famílias, de modo que cada professora se responsabilizou pelo preparo de um dos tópicos do PPP.

Diversas ações foram mobilizadas na instituição, a fim de que os sujeitos pudessem discutir o processo de constituição da região e a organização dos moradores do passado e do presente: vídeos, fotos, pesquisas com as famílias, uma multiplicidade de fontes que revelam as mudanças sofridas e as redes de solidariedade entre os moradores. Espaços que, ao mesmo tempo que se detinham a valorizar a autoestima dos sujeitos que praticam esse lugar, também oportunizavam aos moradores/as, professores/as e alunos/as expressarem outros desejos de mudança, especialmente com relação a violência causada pelo tráfico de drogas e pelos assaltos. Uma relação entre passado e presente que também nos ajuda como orientação para o futuro que reinventamos a todo o momento.

\section{Algumas considerações}

Ao discutirmos sobre as continuidades e descontinuidades dos movimentos sociais e de escolarização de uma região tão peculiar, buscamos superar a inferioridade que lhe foi historicamente conferida. Ao atribuir centralidade aos sujeitos e compreender os sentidos que investem em suas práticas, as "táticas" que mobilizam, "astuciosamente", no seu cotidiano revelam-se uma importante estratégia para perceber "detalhes" por vezes "negligenciáveis" que podem ser decisivos para trazer mais clareza ao objeto desta investigação.

A opção apresenta-se como uma "tática" relevante para ampliarmos novas possibilidades de trabalho, visto que "[...] não se pode falar da região São Pedro, de sua ocupação e das melhorias que vem conquistando, sem relembrar a maneira como a população tem participado de todo o processo" (GURGEL; PESSALI, 2004, p. 103). O movimento dos sujeitos que praticam esse lugar e o que é produzido em suas relações ganham centralidade em nossa análise. 
Buscamos, ainda, uma forma menos hierárquica de concebermos os conhecimentos, a fim de que possamos dar visibilidade aos que já existem, bem como valorizar a produção individual e coletiva de outras formas de conhecer e viver que tragam menos desigualdades sociais, culturais, econômicas e políticas. Reconhecemos, como Santos (2004), que a crítica à racionalidade hegemônica não implica a desqualificação do conhecimento produzido e das conquistas alcançadas, mas uma reflexão a respeito desse conhecimento, de sua produção e de sua utilização. 


\section{Referências}

ANDREATA, Graça. Na lama prometida a redenção. São Paulo: O Recado Editora, 1987. ANDREATA, Graça. No lixo. In: FREITAS, Whelton Pimentel de; ANDREATTA, Graça. Itapoemas. Mariana/MG: Dom Viçoso, 2003.

BENJAMIN, Walter. Magia e técnica, arte e política: ensaios sobre literatura e história da cultura. 7 ed. São Paulo: Brasiliense, 1994. (Obras escolhidas; v. 1).

BLOCH. Marc. Apologia da história: ou o ofício do historiador. Rio de Janeiro: Jorge Zahar, 2001.

CERTEAU, Michel de. A invenção do cotidiano: 1. Artes de fazer. Petrópolis: Vozes, 1994. DIAS, Tavares. São Pedro. Vitória: Secretaria Municipal de Cultura, 2001.

GINZBURG, Carlo. Mitos, emblemas e sinais: morfologia e história. São Paulo: Companhia das Letras, 1989.

GURGEL, Antônio de Pádua; PESSALI, Hesio (Org.). São Pedro, Vitória: um exemplo para o mundo. Vitória: Contexto Jornalismo \& Assessoria/Instituto Huah/Núcleo de Projetos Culturais e Ecológicos, 2004.

JOSGRILBERG, Fabio Botelho. Cotidiano e invenção: os espaços de Michel de Certeau. São Paulo: Escrituras, 2005.

LUGAR de toda pobreza. Produção: Amylton de Almeida / Rede Gazeta: Vitória, ES, 1983. (20 minutos).

NUNES, Kezia Rodrigues. Práticas curriculares da Educação Física na Educaşão Infantil: um estudo de caso. 2007. Dissertação (Mestrado em Educação Física) - Universidade Federal do Espírito Santo, Vitória, 2007.

SANTOS, Boaventura de Sousa. Um discurso sobre as ciências. São Paulo: Cortez, 1985.

SANTOS, Boaventura de Sousa. Para uma sociologia das ausências e uma sociologia das emergências. In: SANTOS, Boaventura de Sousa (Org.). Conhecimento prudente para uma vida decente: um discurso sobre as ciências revisitado. São Paulo: Cortez, 2004. p. 777-821. 


\section{Notas}

1 A pesquisa contou com financiamento UFES/Petrobras (modalidade bolsa de mestrado). As ideias e os conteúdos expressos no texto são de nossa responsabilidade.

2 A Ilha das Caieiras foi, até a metade do século XX, um lugar remoto na geografia de Vitória, reduto de lavadeiras, pescadores e uma fábrica de cal - daí o nome caieiras -, de onde se estendia, na direção do interior, o manguezal fechado (GURGEL; PESSALI, 2004). 3 A região da Grande Vitória é constituída pelos municípios de Cariacica, Vitória, Viana, Vila Velha e Serra.

4 Com a produção do cineasta capixaba Amylton de Almeida, foram divulgados, em 1983, um filme e um livro com o mesmo nome. O documentário, exibido em todo o país, teve o intuito de acompanhar a trajetória de uma família de catadores de lixo durante quase um ano. 5 A partir de 1999, com a instalação da Policlínica São Pedro, outros serviços especializados foram incluídos, especialmente de diagnóstico (raios-X, eletrocardiograma, exames laboratoriais), de atenção às áreas crônico-degenerativas (cardiologia, endocrinologia, oftalmologia, fisioterapia e nutrição), psicossocial (psiquiatria, neurologia, assistência social e psicológica) e do aparelho reprodutor (ginecologia e urologia).

6 Trata-se do Programa de Erradicação da sub-habitação, que não conquistou a adesão da comunidade. Trazia propostas previamente definidas em Brasília, por um grupo de engenheiros, arquitetos e assistentes sociais do governo. Para ser parcialmente implantado em São Pedro I, o Promorar foi amplamente modificado (GURGEL; PESSALI, 2004).

7 Optamos por não revelar o nome da instituição pesquisada e manter como identificação parte do nome original, valorizando a iniciativa dos moradores. A educadora que empresta seu nome ao CMEI nasceu em 21 de junho de 1911 e faleceu em 26 de agosto de 1985. Formou-se na Escola Normal D. Pedro II e foi professora alfabetizadora na cidade e no interior.

8 Cf. <http://www.vitoria.es.gov.br>. Acesso em: 3 abr. 2007.

9 Os documentos do CMEI fazem menção a algumas pessoas que se destacaram pelo engajamento na constituição dessa instituição. Algumas ainda trabalhavam no CMEI como professoras, merendeiras e ASGs, no período desta pesquisa.

Recebido: 25/11/2010

Aprovado: 09/06/2011

Contato:

Universidade Federal do Espírito Santo

Centro de Educação

Departamento de Linguagens, Cultura e Educação

Avenida Fernando Ferrari, s/n

Goiabeiras

CEP 29060-900

Vitória, ES

Brasil 